+ Chandy MJ, Rajshekhar V, Prakash S, et al. Cysticercosis causing single small CT lesions in Indian patients with seizures. Lancet 1989-1:390-1.

Rajshekhar V, Abraham J. Disappearing CT lesions in Indian parients with epilepsy. F Neurol Neurosurg Psychiatry 1990;53:818-9.

6 Ahuja GK, Beghari M, Prasad K, Goulatia RK, Jailkham B. Disappearing CT lesions in epilepsy: is tuberculosis or cysticercosis the cause? $\mathcal{f}$ Neurol Neurosurg Psychiatry 1989;52:915.

7 Zegers De Beyl D, Hermanus N, Colle H, Goldman S. Focal scizures with reversible hypodensity on the CT scan 7 Neurol Neurosurg Psychiatry $1985 ; 48: 187-7$.

8 Feinstein A, Ron M, Wessely S. Disappearing brain lesions, psychosis and epilepsy: a report of two cases. F Neurol Neurosurg Psychiatry 1990;53:244-8. Minguetti G, Ferreira MVC. Computed tomography in neurosysticercosis I Neurol Neurosurg Psychiatry 1983;46:936-42.

(Accepted 6 February 1991)

\section{Evaluation of a diagnostic algorithm for heart disease in neonates}

\author{
Rodney C G Franklin, David J Spiegelhalter, Fergus J Macartney, Kate Bull
}

\section{Abstract}

Objective-To develop, test, and validate an algorithm for diagnosing disease in neonates during an over the telephone referral to a specialist cardiac centre.

Design-A draft algorithm requiring only data available to a referring paediatrician was generated. This was modified in the light of a retrospective review of case records. A questionnaire to elicit all the data required by the algorithm was then generated. There followed a prospective three phase evaluation during consecutive over the telephone referrals. This consisted of $(a)$ a conventional phase with unstructured referral consultations, $(b)$ a phase with referrals structured around the questionnaire but independent of the algorithm, and $(c)$ a validation phase with the algorithm (and its previous errors) available during the referral consultation.

Setting-59 paediatric centres in south east England and a central specialist paediatric cardiology unit.

Patients-Consecutive neonates (aged $<\mathbf{3 1}$ days) referred with suspected heart disease. The retrospective review was of records of 174 neonates from 1979. In the prospective evaluation (1987-90) the conventional phase comprised 71 neonates (over 5.5 months), the structured phase 203 neonates (over 14 months), and the validation phase 195 neonates (over 12 months).

Main outcome measures-Diagnostic accuracy (assigning patients to the correct diagnostic category (out of 27)), of the referring paediatrician, the specialist after the referral consultation, and the algorithm as compared with the definitive diagnosis by echocardiography at the specialist centre, and score for the appropriateness of management in transit .

Results - Simply structuring the consultation by questionnaire (that is, proceeding from the conventional phase to the structured phase) improved the diagnostic accuracy of both paediatricians (from $34 \%(24 / 71$ cases $)$ to $48 \%(97 / 203)$ correct $)$ and
Hospital for Sick Children, Great Ormond Street, London WC1N 3JH research fellow

Fergus J Macartney, FRCP, professor of paediatric cardiology

Kate Bull, MRCP, senior cardiology

MRC Biostatistics Unit, Cambridge CB2 2BW

David J Spiegelhalter, PHD, senior statistician

Correspondence and requests for reprints to: Dr Bull, thoracic unit.

BMF 1991;302:935-9
Rodney C G Franklin, MRCP, lecturer in paediatric

centre in poor condition, no matter how aggressive their subsequent management..$^{1-3}$ Ideally, appropriate management should begin at the referring hospital and continue in transit to the specialist centre, which may take several hours. ${ }^{4}$ Despite the dangers of inadequate, inappropriate, or overzealous treatment, ${ }^{56}$ however, management must usually be initiated on the basis of a presumptive clinical diagnosis, typically arrived at by a non-specialist without special training in cross sectional echocardiography (by which a definitive diagnosis is ultimately made).

District paediatricians refer the patients by telephone and discuss starting supportive treatment. We aimed at developing, testing, and validating a diagnostic aid for use during this over the telephone consultation. Its diagnostic accuracy and implications for management in transit would then be compared with conventional diagnostic and referral methods, with the aim of improving the condition of neonates arriving at specialist centres.

\section{Patients and methods}

Retrospective review-The clinical findings and provisional diagnoses of all 174 consecutive neonates who presented to the Hospital for Sick Children at under 31 days of age in 1979 were reviewed. In 1979 neither cross sectional echocardiography nor prostaglandin was available and our cardiologists made an initial diagnosis based on data comparable to those available to referring paediatricians during this study.

Conventional phase-Conventional over the telephone referrals are unstructured by questionnaires or algorithms. Prospectively, at the end of each of 71 consecutive referral conversations over 5.5 months, both the general paediatrician and the paediatric cardiologist were asked to specify a diagnosis based on the clinical findings and investigations discussed. The final diagnosis was determined by cross sectional echocardiography after the child's transfer.

\section{DIAGNOSTIC ALGORITHM}

An algorithm for diagnosing congenital heart disease correct). The algorithm (structured phase) would have been even more accurate ( $78 \%$ (158/203 cases); $\mathbf{p}<\mathbf{0 . 0 1})$. Management scores in the structured phase were also better than in the conventional phase $(80 \%(162 / 203$ cases $) v 58 \%(41 / 71)$ appropriate; $\mathbf{p}<\mathbf{0 . 0 1})$. Management scores would have improved to $91 \%$ appropriate $(185 / 203 ; \mathrm{p}<0.001)$ had the algorithmic diagnoses dictated management. The superiority of the algorithm was maintained but not bettered in the validation phase.

Conclusions-Applying the algorithm should reduce the morbidity and mortality of neonates with critical heart disease by aiding clinicians in therapeutic decisions for in transit care.

\section{Introduction}

The outcome of neonates with critical congenital heart disease is prejudiced if they arrive at a specialist aid. The algorithm required only basic clinical data available to any clinician dealing with a neonatenamely, results of a clinical examination, an electrocardiogram, chest $x$ ray appearances, and, sometimes, arterial blood gas tensions. In the light of the retrospective review this draft algorithm was amended and a series of defaults created to allow for incomplete information so that it could be run for all patients (see appendix). At this stage the algorithm, in near final form, distinguished 27 diagnostic categories, including lung disease masquerading as heart disease and disturbances of the transitional circulation.

For prospective testing a questionnaire to elicit the data required by all pathways of the algorithm was generated. The study was explained by letter to the 115 paediatricians who referred neonates to our institution, enclosing a sample questionnaire. 
Structured phase-The next 203 consecutive over the telephone referrals over 14 months were structured around the questionnaire; the algorithm was not referred to and had not been seen by either party. As before, both clinicians were asked to come to a diagnostic conclusion at the end of their conversation and the true diagnosis was determined by cross sectional echocardiography after arrival of the child. The data obtained by questionnaire were subsequently run through the algorithm to obtain an algorithmic diagnosis. Data from 377 patients were by then available and the algorithm and its defaults were trivially modified (improving accuracy by about $2 \%$ ) into a final form (see figure) for use in prospective validation. As a guide to the local strengths and weaknesses of the algorithm, displayed beside each diagnosis were also the true diagnoses in patients reaching this point during the structured phase.

Validation phase-During the next 195 consecutive referrals over 12 months the specialist could for the first time refer to the algorithm during the telephone consultation. The clinicians' declared provisional diagnosis might or might not be influenced by the algorithm. With the definitive diagnoses available the diagnostic accuracy of the clinicians alone, the clinicians obliged to complete a questionnaire, and the clinicians influenced by the algorithm could be compared, both with that of each other and then with the accuracy of the algorithm run from the questionnaire or directly at the time of referral.

\section{IN TRANSIT MANAGEMENT}

The main aim of the algorithm was to improve treatment in transit, though an incorrect diagnosis would not necessarily lead to inappropriate treatment. A cross tabulation of five management strategies against each diagnostic category was prepared. A group of specialists gave each strategy a score of 1 (optimal) to 4 (potentially dangerous) in respect of each diagnostic subdivision, taking into account whether the neonate seemed critically ill (table I). The table

TABLE I - Two examples of cross tabulation of diagnostic category against appropriateness of management strategy. Figures are managment scores

\begin{tabular}{|c|c|c|c|c|c|}
\hline & $\begin{array}{c}\text { Pulmonary } \\
\text { vasodilatation }\end{array}$ & $\begin{array}{l}\text { Patent ductus } \\
\text { arteriosus open }\end{array}$ & $\begin{array}{l}\text { Patent ductus } \\
\text { arteriosus open } \\
\quad+\text { diuretic } \\
\text { +inotrope }\end{array}$ & $\begin{array}{l}\text { Antiheart } \\
\text { failure }\end{array}$ & $\begin{array}{c}\text { No } \\
\text { treatment }\end{array}$ \\
\hline Hypoplastic left heart syndrome & $\begin{cases}\text { Sick } & 3 \\
\text { Well } & 3\end{cases}$ & $\begin{array}{l}2 \\
1\end{array}$ & $\begin{array}{l}1 \\
2\end{array}$ & $\begin{array}{l}3 \\
2\end{array}$ & $\begin{array}{l}4 \\
3\end{array}$ \\
\hline Simple transposition of great arteries & $\begin{cases}\text { Sick } & 3 \\
\text { Well } & 3\end{cases}$ & $\begin{array}{l}1 \\
3\end{array}$ & $\begin{array}{l}2 \\
3\end{array}$ & $\begin{array}{l}4 \\
3\end{array}$ & $\begin{array}{l}4 \\
1\end{array}$ \\
\hline
\end{tabular}

Management strategies - Pulmonary vasodilatation $=0 x y g e n \pm$ ventilation \pm tolazoline \pm dopamine; patent ductus arteriosus open $=$ prostaglandin \pm ventilation (appropriate for conditions with duct dependent pulmonary blood flow); patent ductus arteriosus open + diuretic + inotrope = prostaglandin with inotropic support and diuretics \pm ventilation (appropriate for conditions with duct dependent systemic blood flow); antiheart failure $=$ diuretics or digoxin, or both \pm oxygen.

Management scores $-1=$ Optimal, $2=$ appropriate, $3=$ inappropriate, $4=$ potentially dangerous.

TABLE II -Comparisons of diagnostic accuracy and appropriateness of in transit management

\begin{tabular}{|c|c|c|c|c|}
\hline & $\begin{array}{c}\text { Retrospective } \\
\text { review } \\
(\mathrm{n}=174\end{array}$ & $\begin{array}{c}\text { Conventional } \\
\text { phase } \\
(\mathrm{n}=7 \mathbf{1})\end{array}$ & $\begin{array}{l}\text { Structured } \\
\text { phase } \\
(\mathrm{n}=203)\end{array}$ & $\begin{array}{c}\text { Validation } \\
\text { phase } \\
(n=195)\end{array}$ \\
\hline \multicolumn{5}{|c|}{ Diagnostic accuracy-No $(\%)$ correct for 27 diagnostic categories } \\
\hline Paediatrician & & $24(34)$ & $97(48)$ & $88(45)$ \\
\hline Specialist & $115(66)$ & $38(54)-$ & $-130(64)]^{\star \star \star}$ & $125(64)$ \\
\hline Algorithm & $148(85)$ & & $158(78)$ & $148(76)$ \\
\hline \multicolumn{5}{|c|}{ In transit management $-\mathrm{No}(\%)$ optimal or appropriate (score 1 or 2} \\
\hline Paediatrician/specialist & & $41(58)$ & $\left.\overline{162}^{\star \star \star}(80)\right\}^{\star \star \star}$ & $162(83)$ \\
\hline Algorithm derived & & & $185(91)$ & $181(93)$ \\
\hline
\end{tabular}

${ }^{\star} \mathrm{p}=0 \cdot 2 .{ }^{\star \star} \mathrm{p}<0 \cdot 05 .{ }^{\star \star \star} \mathrm{p}<0 \cdot 001$ served only for evaluation; the table of suggested strategies was not available to the clinicians in practice.

The appropriateness of the treatment each baby actually received in each phase could thus be scored with reference to the optimal treament that would have been appropriate for the true diagnosis. The management score corresponding to the diagnosis the algorithm would have offered was also obtained and all scores compared.

\section{COMPUTERS AND STATISTICAL METHODS}

The algorithm, its defaults, and the questionnaire data were programmed into a microcomputer so that the algorithm could be modified interactively to improve its diagnostic accuracy and minimise inappropriate management; the form of the algorithm was not optimised by statistical techniques. ${ }^{7}$ Contrasts between diagnostic and management performance within the structured phase were tested by McNemar's test for paired comparisons, and comparisons between structured and conventional phases were by $\chi^{2}$ tests.

\section{Results}

The figure shows the final algorithm as available during the validation phase. It incorporates information on the accuracy of all algorithmic diagnoses for the 203 patients in the structured phase.

Diagnostic accuracy (table II) - When faced with a neonate with suspected heart disease and only clinical findings and basic test results available (chest $x$ ray film, electrocardiogram, arterial blood gas values) the paediatric cardiologists assigned patients correctly to one of the 27 diagnostic categories in $66 \%$ of cases $(115 / 174$ neonates in the retrospective review) and the general paediatricians correctly in $34 \%$ of cases $(24 / 71$ neonates in the conventional phase). Using the general paediatrician's account of physical signs and investigation findings, specialists arrived at the correct diagnosis over the telephone in $54 \%$ (38) of the same 71 patients. The exercise of structuring the telephone consultation with a questionnaire improved the diagnostic performance of both the general paediatricians and the specialists to whom they described the cases to $48 \%$ (97/203 cases) and 64\% (130/203) respectively. The clinicians' performance was virtually unchanged during the validation phase. Using data elicited by the specialist from the general paediatrician by questionnaire, the algorithm gave an overall diagnostic accuracy better than either clinician $(78 \% ; 158 / 203$ cases $)$. This performance was maintained during the validation phase $(76 \% ; 148 / 195)$. Using the clinical data recorded by the specialists in 1979 , the final algorithm performed with even better accuracy $(85 \% ; 148 / 174$ cases $)$.

In transit management (table II)-The clinicians together decided on optimal or appropriate management (score 1 or 2) more often in the structured phase than in the conventional phase $(80 \%$ (162/203 cases) $v 58 \%(41 / 71))$. Had the algorithmically derived diagnosis been followed management of patients would have further improved to $91 \%$ (185/203 cases) during the structured phase or to $93 \%(181 / 195)$ during the validation phass.

\section{CAUSES OF DIAGNOSTIC ERROR}

Diagnostic errors may not lead to inappropriate treatment. Although the algorithmically derived management recommendations scored better than clinicians' recommendations, the algorithm would have been responsible for inappropriate treatment in 25 of the 398 patients $(6 \%)$ and potentially dangerous treatment in seven patients $(2 \%)$. There were three reasons for diagnostic failure by the algorithm: atypical presentation, absent data, and observer error

Atypical presentation-A finding atypical for a 


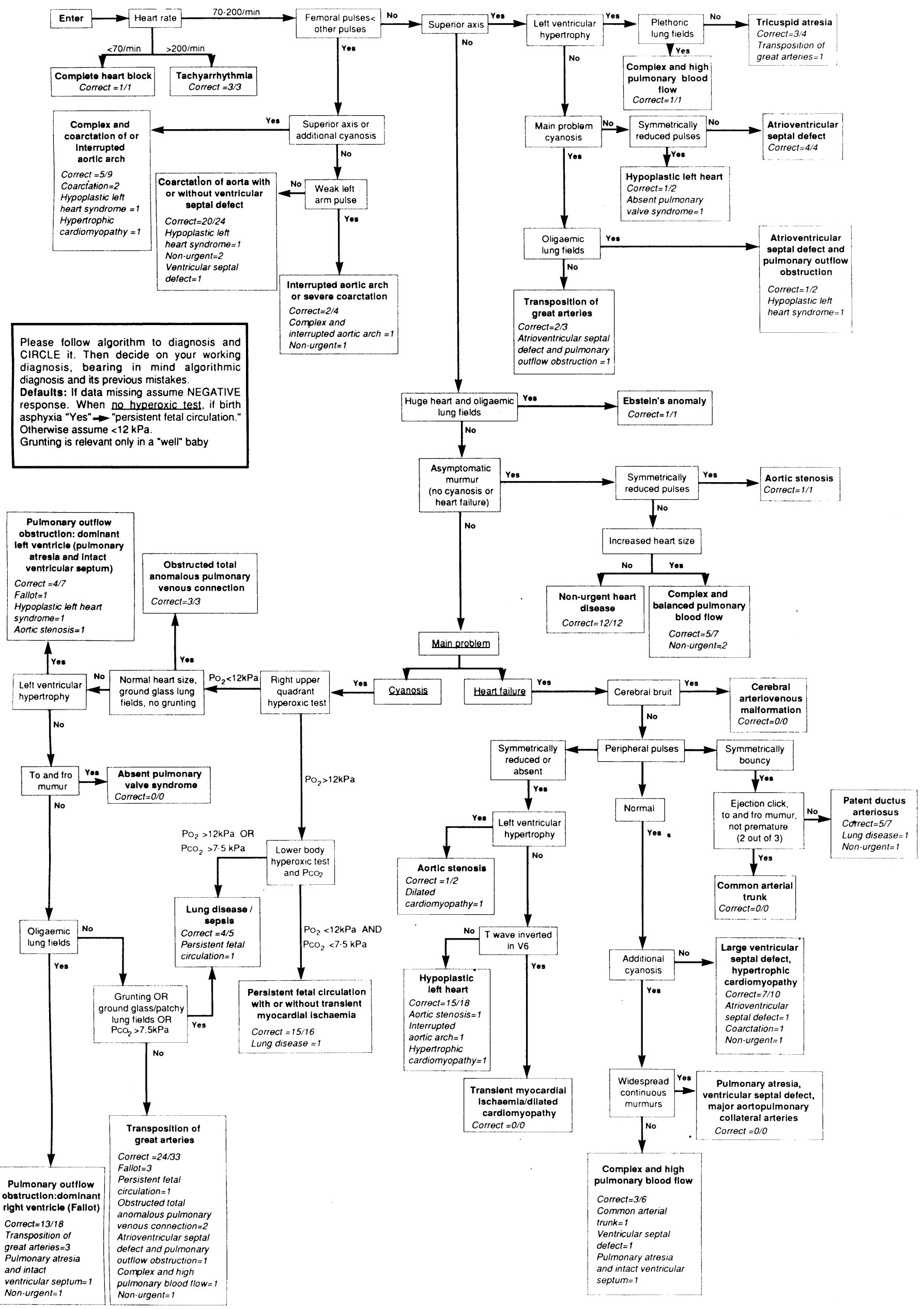

Diagnostic algorithm for over the telephone consultation as used in validation phase. Algorithm discriminates 27 diagnostic categories in neonates and is validated for use by specialist paediatric cardiology centre only. Under each diagnostic category are numbers of cases correctly diagnosed during structured phase (203 neonates). Then are listed correct diagnoses in those in which algorithmic diagnosis was wrong 
particular disease - for example, left ventricular hypertrophy in a patient with tetralogy of Fallot-accounted for a wrong diagnosis in 45 patients $(11 \%)$; six would have received inappropriate and one potentially dangerous treatment.

Absent data-When data are not obtained the algorithm uses a series of defaults. These were chosen on the basis of previous data to bring as many patients as possible to the correct diagnosis-for example, when no electrocardiogram is available to differentiate between critical aortic stenosis and hypoplastic left heart syndrome the default leads to the second diagnosis. There were eight patients (2\%) misdiagnosed because of missing data. Two of these would have received inappropriate and one potentially dangerous treatment.

Observer error-Misinterpretation of physical signs or chest $x$ ray appearances led to an incorrect algorithmic diagnosis in 35 cases $(9 \%)$. Sixteen of these patients would have received inappropriate and five potentially dangerous treatment. Of three patients who had the combination of atypical presentation and observer error, one would have received inappropriate treatment.

\section{Discussion}

Attempts to decrease the mortality of neonates with congenital heart disease have usually focused on different strategies for their surgical management. Some patients die, however, before surgery can be attempted, and the outcome of others is prejudiced by serious preoperative decompensation, ${ }^{1-3}$ avoidable if early supportive treatment is begun. Surgery within one to two hours of arrival is rarely undertaken at our centre because alternative manoeuvres, such as drugs or ventilation, are usually of more benefit. These are almost always available at referring hospitals and could be supervised during the transfer of the baby. The problem is to match the patient to the appropriate management at a stage when the diagnosis is uncertain and the patient is potentially unstable.

Our study has shown that even structuring the referral telephone interview around a questionnaire significantly improves diagnostic accuracy and management of neonates with congenital heart disease. (We acknowledge that even during the conventional phase the specialists knew their performance was being monitored. It is well established that audit alone can improve clinical performance ${ }^{x y}$-the "Hawthorne effect.") We hoped that the algorithm, which incorporates expert understanding of a complicated diagnostic process, would further improve diagnosis and management in transit.

\section{ISSUES IN THE GENERATION OF THE ALGORITHM}

Size - When creating the algorithm it was important not to produce a tree that was too complicated. By simply adding branches for each new case that was not already accounted for it would have been possible to get all the "training" cases right, but this could be useless for prediction. Therefore, we developed informal criteria to lump and split diagnoses and trade off complexity against accuracy of past cases.

Evaluation-Any diagnostic aid, whether implemented on paper or on a microcomputer, needs to be acceptable to users at both ends of the telephone, satisfy "expert" authority with regard to its quality, and be seen to be complementary, not threatening, to the clinician in management decisions. "Many authors have generated algorithms but few of these $\mathrm{e}^{\text {" have been }}$ rigorously evaluated by comparison with conventional methods, although this is important if clinicians are to be convinced of their usefulness. For validation Wasson et al emphasised that the data should be elicited in usual practice and that the final diagnoses should be independently obtained."' This has been possible for neonates with heart disease, in whom the echocardiographic diagnosis is definitive.

Medicolegality - The algorithm is designed to be used as a diagnostic aid by the doctor at a specialist centre receiving a telephoned referral concerning the transfer of a neonate with suspected heart disease. It is only in this context that the algorithm was evolved and the validation exercise conducted. A different algorithm would need to be tested to help the neonatologist faced with the differential diagnosis of cyanosis or shock. Given that the algorithm is used in the appropriate context, details of its previous performance are available to the specialist user. Conviction about the provisional diagnosis and the choice of appropriate treatment then becomes the province of the doctors at both centres. Had the alternative (and probably simpler) approach of producing an algorithm to dictate treatment directly been chosen there might be doubts about the medicolegal liability, when sooner or later the algorithm offered a dangerously inappropriate treatment.

DISADVANTAGES AND LIMITATIONS OF THE ALGORITHMIC APPROACH

Although simple, the algorithmic approach is rather unforgiving. An incorrect diagnosis can be arrived at after a single unexpected response, due to either an atypical presentation or observer error. This will inevitably occur and misdiagnosis will sometimes suggest inappropriate treatment.

Algorithms may also be criticised for not using all the data available on a patient, particularly when compared with a more statistical approach in which evidence is weighed rather than logical conclusions drawn. A probabilistic approach has been explored with respect to congenital heart disease in nonneonates, though none of the resultant diagnostic aids were formally tested in clinical practice. ${ }^{13-15}$ Such purely probabilistic techniques neglect the expert knowledge incorporated in the structure of the algorithm and are also bound to perform poorly for rare conditions. We generated such a simple probabilistic model for neonatal diagnosis, assuming the clinical findings to be independent within each disease category and incorporating "expert" assessments of the frequencies of findings within disease categories. Using our data from the structured phase, the model was accurate in $60 \%$ (122) of the 203 cases, rising to only $61 \%$ (124) when the incoming data were allowed to adjust the initial frequencies derived from the experts. ${ }^{16}$ This indicates that naive statistical modelling is an inappropriate tool for dealing with this complex, though well understood domain.

\section{STRATEGIES FOR IMPROVEMENT}

Within an algorithmic framework a statistical procedure such as classification and regression trees ${ }^{\text {- }}$ might be used to derive a new algorithm from the data alone. Alternatively an algorithm might focus on a disease contender, then a probabilistic scoring system used to identify conflicting evidence and suggest further questions to confirm or deny the hypothesis. A more ambitious aim would be to construct a "causal network" model which reflects what is known about the anatomy of the various diseases and the processes by which the anomalies give rise to the clinical findings. ${ }^{1 \times}$ It has been established that bayesian probabilistic reasoning and updating of probability assessments with each case ("learning") can be carried out on such networks. "1" This could lead to an integrated system tha* serves as a physiological model, a clinical database, and a diagnostic management adviser. This is an important topic for future research and is currently being pursued. 
We are grateful for the cooperation and patience of the resident medical staff of the paediatric cardiology unit at the Hospital for Sick Children, without whom this study would not have been completed: Drs Ian Sullivan, Steve Cooper, Paul Oslizlok, Anna Colli, Bill Balaji, Vivienne Miall-Allen, and Seamus Cullen. RCGF was funded as a junior research fellow by the British Heart Foundation (grant No F126), and FJM was supported by the Vandervell and British Heart Foundations.

\section{Appendix}

DEFAULTS FOR ALGORITHM WHEN DATA MISSING

(1) In general when data are absent assume answer is negative. (2) "Sick" implies a pH of less than $7 \cdot 29$ or a base excess of less than $-0.7 \mathrm{mmol} / \mathrm{l}$ or clinically very unwell despite a reasonable blood gas tension.

(3) When the patient is sick grunting has no diagnostic relevance.

(4) When data for $\mathrm{PCO}_{2}$ are absent assume value is less than $7 \cdot 5$ $\mathrm{kPa}$

(5) When hyperoxic test data are completely absent assume $\mathrm{Po}_{2}$ is less than $12 \mathrm{kPa}$ unless patient is under 3 days of age with a history of birth asphyxia, when go to "persistent fetal circulation"; when hyperoxic test data are derived from a sample from only one site (that is, data are incomplete) assume value at other site is the same unless patient is under 3 days of age with a history of birth asphyxia, when go to "persistent fetal circulation."

1 Bove EL, Bull C, Stark J, de Leval MR, Macartney FJ, Taylor JFN Congenital heart discase in the neonate: results of surgical treatment. Arch Dis Child 1983;58:137-41.

2 Rubay J, de Leval MR, Bull C. To switch or not to switch: the Senning alternative. Circulation 1988;78 suppl III :1-4.

3 Franklin RCG, Spiegelhalter DJ, Anderson RH, et al. Double inlet ventricle presenting in infancy: results of palliative surgery. 7 Thorac Cardiovasc Sur in press in.

+ Cook DH, Rose V, Fay J, et al. Impact of specialty centres on neonatal heart disease, Ontario, 1975. Can f Public Health 1978:69:297-301.

5 Lewis AB, Freed MI), Heymann MA, Roehl SL, Kensey RC. Side effects of therapy with prostaglandin $E_{1}$ in infants with critical congenital heart disease. Circulution 1981:64:893-8.

6 Danford DA, Gutgesell HP, MCNamara DG. Application of information theory to decision analysis in potentially prostaglandin-responsiven neonates. 7 Am Coll Cardiol 1986:8:1125-30.

7 Goldman L, Weinberg M, Weisberg M, et al. A computer derived protocol to aid in the diagnoses of emergency room patients with acute chest pain. N Engl 7. Med 1982;307:588-98.

8 Adams ID, Chan M. Clifford PC, el al. Computer aided diagnosis of acute abdominal pain: a multicentre study: $B M 7$ 1986:293:800-4
9 Roethligsburger FJ, Dickson WJ. Management and the worker Cambridge, Massachusets: Harvard University Press, 1939

10 Teach RL, Shortliffe EH. An analysis of physician attitudes regarding computer-based clinical consultation systems. Comput Biomed Res 1981;14: $542-58$

11 Goldman L, Cook EF, Brand DA, et al. A computer protocol to predict myocardial infarction in emergency department patients with chest pain. N Engl f Med 1988;318:797-803.

12 Wasson JH, Sox HC, Neff RK, Goldman L. Clinical prediction rules: applications and methodological standards. N Engl f Med 1985;313:793-9.

13 Warner HR, Toronto AF, Veasy LG, Stephenson RS. A mathematical approach to medical diagnosis: application to congenital heart disease. YAMA 1961:177:177-83.

14 Reale A, Maccacaro GA, Rocca E, et al. Computer diagnosis of congenital heart disease. Comput Biomed Res 1968;1:533-49.

15 Warburton D, Rehan M, Shinebourne EA. Selective criteria for differential diagnosis of infants with symptoms of congenital heart disease. Arch Dis Child 1981;56:94-100.

16 Franklin RCG, Spiegelhalter DJ, Macartney FJ, Bull C. Combining clinical judgement and statistical data in expert systems: over-the-telephone management decisions for critical congenital heart disease in the first month of life. Int f Clin Monit Comput 1989;6:157-66.

17 Breiman L, Friedman JH, Olshen RA, Stone CJ. Classification and regression trees. Belmont, California: Wadsworth International Group, 1984

18 Schwartz. WB, Patil RS, Szolovits P. Artificial intelligence in medicine: where do we stand? N Eingl F Med 1987;316:685-8.

19 Lauritzen SL, Spiegelhalter DJ. Local computations with probabilities on graphical structures and their application to expert systems. Fournal of the Roval Statistical Society 1988:50(ser B):157-224.

(Accepted 28 fanuary 1991

\section{Correction}

Glucose tolerance and blood pressure: long term follow up in middle aged men

An editorial error occurred in this article by Dr V V Salomaa and others ( 2 March, p 493). The formula for calculating confidence intervals for the risk ratios given in the methods section was incorrect; the correct formula is $\mathrm{e}(\beta \pm(1.96) \operatorname{SE}(\beta))$.

By how much does dietary salt reduction lower blood pressure? III - Analysis of data from trials of salt reduction One editorial and four authors' errors occurred in this article by Dr M R Law and others (6 April, p 819). The y axis of figure 4 depicts mortality from stroke and not mortality from ischaemic heart disease as published. The values in the last sentence of the results section of the abstract are $22 \%$ and $16 \%$ and not $26 \%$ and $15 \%$, and the value in the last sentence of the conclusions section of the abstract is 75000 and not 70000 . Finally, in the last column of the table the third value from the bottom is $3.9(8.4)$ and not $-3 \cdot 9(8 \cdot 4)$ as published.

\section{ONE HUNDRED YEARS AGO}

Dwellers in London may now be of good cheer, for $\mathrm{Mr}$. Ritchie has at last made a serious attempt to remove some of their worst grievances, and to evolve order out of the chaos which now represents the sanitary administration of the metropolis. The removal of slush and snow will be in future superintended by the local authority; salt will no longer be allowed to form freezing mixtures on our streets in winter, nor dust-bins to scatter their noxious contents through the air in broad daylight. Nuisances, unsound meat, smoke, water supply, and disinfection are dealt with in summary and drastic fashion, and a very practical clause makes heavy penalties recoverable from anyone affected with or convalescent from infectious disease who milks cows, picks fruit, or handles any article of food in a way which is likely to communicate contagion.

These and the other provisions of the Bill are to be carried out by a largely-increased staff of inspectors, and, following the excellent precedent of the Scotch Local Government Act, medical officers of health are to be hereafter removable only by the authority of the Local Government Board. Mr. Ritchie's speech in introducing his two Bills for the amendment and consolidation of the public Acts of London was clear, conciliatory, and able, and we congratulate him sincerely on the favourable reception it met with from all parts of the House. One or two warning notes of criticism were sounded during the discussion, as when the London members urged with much force that it is putting the cart before the horse to introduce such a Bill before the establishment of district councils; and when several speakers urged the propriety of relieving householders from the ill-performed duty of clearing away snow from their doorsteps and pavements. But, on the whole, a most friendly feeling prevailed, and it was agreed that detailed criticism had better be reserved for the Grand Committee on Law, to which the Bill has been referred; we are sanguine that when it comes back to the House, strengthened and improved by amendment and compression, it will soon take its place on the Statute Book as a measure which will contribute largely to the health, comfort, and convenience of the inhabitants of London.

We shall watch the Bill carefully as it passes through Committee, and report progress from time to time. We note with pleasure Mr. Ritchie's expressed desire to accept reasonable suggestions for its "betterment," and the Parliamentary Bills Committee will immediately take steps with the view of helping him to complete with credit and success a task which has so well begun. (British Medical Fournal 1891;i:810) 